\title{
Decreasing of the manufacturing time for a thermoforming mold by applying the DFM principles
}

\author{
Ancuţa Păcurar ${ }^{1, *}$, Răzvan Păcurar $^{1}$, Beáta Eröss $^{1}$, Florin Popister $^{2}$, and Calin Ciprian Otel $^{3}$ \\ ${ }^{1}$ Technical University of Cluj-Napoca, Department of Manufacturing Engineering, Romania \\ ${ }^{2}$ Technical University of Cluj-Napoca, Department of Design and Robotics Engineering, Romania \\ ${ }^{3}$ Technical University of Cluj-Napoca, Department of Industrial Engineering and Management
}

\begin{abstract}
In this paper it is analyzed a product machined at the S.C. ULMA PACKAGING S.A. company, which is a "Thermoforming mold" used in order to obtain plastic containers in which the food or non-food product is packed, making part of a thermoforming machine called TFS 200. The aims of this paper are to determine the optimal technological parameters and to study the effects of the DFM principles and the optimal tool path strategy usage on manufacturing time of the "Thermoforming mold". A redesign of the thermoforming mold is presented based on the failed rules and recommendations given by the DFM program and followed by the analysis of the DFM's benefic effect on the manufacturing time.
\end{abstract}

\section{Introduction}

Winning in today's global marketplace requires more than just creating innovative product designs. In order to succeed, the researchers must design products in a right manner from the first time for optimal manufacturing, cost, quality, time, and functionality. DFM (Design for Manufacturing) is a methodology for product development or product improvement projects in which designers and manufacturing engineers work together instead of working separately. The two groups design the product's manufacturing and assembling processes at the same time they design the product itself. As a result of their teamwork and focus on DFM axioms, they create a product that is well-designed, costefficient, and easy to produce and maintain $[1,2]$. There are many CAD - integrated design for manufacturing programs which help to identify and correct downstream issues early in the design stage, leading to the reduction of the cycle time and, in turn, resulting in highquality products with lower product development costs. One of these programs is called DFMXpress. In the following, a design for manufacturing analysis will be presented how it was realized by using DFMXpress in order to identify and eliminate the critical design issues of the thermoforming mold, that increase the manufacturing complexity and cost.

\footnotetext{
${ }^{*}$ Corresponding author: ancuta.costea@,tcm.utcluj.ro
} 


\section{Design for manufacturing analysis of the thermoforming mold by using DFMXpres}

In this paper it is studied a product manufactured by the Ulma Packaging Company which is called "Thermoforming mold", presented in Figure 1. This thermoforming mold is used in order to obtain plastic containers in which the food or non-food product is packed, Figure 2. The thermoforming mold is part of a thermoforming machine TFS 200, presented in Figure 3, designed to pack food or non-food products.

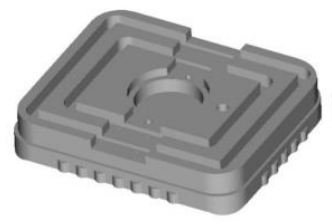

Fig. 1. Analyzed product "thermoforming mold".

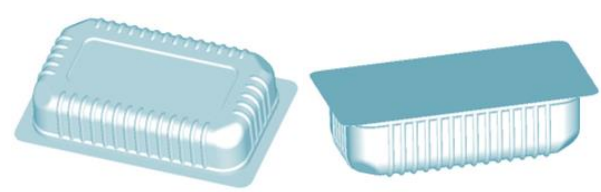

Fig. 2. The obtained plastic food-container after thermoforming process.
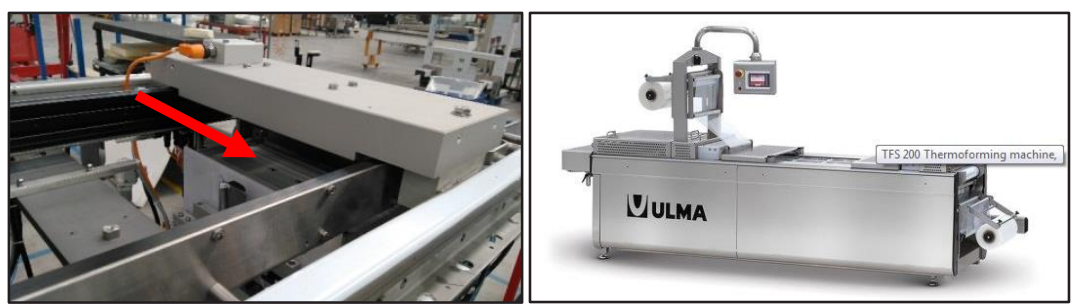

Fig. 3. TFS 200 - Thermoforming machine.

An important step of the designing process is the material selection. In this case, the part is made of aluminum alloy EN-AW-5083 H111 which is known for its exceptional performance in extreme environments because it is highly resistant to the chemical attack that might occur in industrial chemical environments. It is very important to take into consideration the fact that the presented part needs to be coated by industrial Teflon in order to eliminate the possibility of sticking of the foil on the preheated thermoforming mold.

First of all, in order to determine the manufacturing time of the "Thermoforming mold", it was necessary to realize the CNC program required for this issue. In this case, EdgeCam 2014 R2 was used to generate the necessary tool paths in order to obtain the final part [3, 4]. Two different tool path strategies were used on specific geometries of the considered part (Figure 4), the aim of this being the determination of the adequate tool path which will guarantee lower machining time.
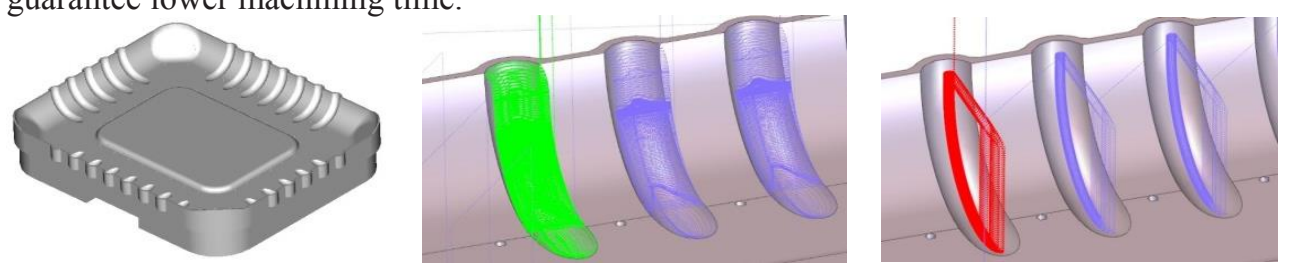

Fig. 4. The analyzed tool path strategies in the case of the thermoforming mold.

Secondly, the thermoforming mold was analyzed from the design for manufacturing point of view using DFMXpress software. After obtaining a redesigned part based on the recommendations of the DFMXpress software, the machining method of the part was 
changed using less special tools and more tools with higher diameter. These modifications had a significant influence on the machining time.

DFMXpress is a rules-based Solidworks add-in that allows the designer to compare its files against known, good design for manufacturing rules. Within Solidworks, the DFMXpress add-in was opened, the Rule File was selected and the desired values for DFMXpress check were set. For Manufacturing Process the "Mill/Drill only" option was chosen, taking into consideration the fact that the thermoforming mold is a CNC milled part. DFMXpress functionality includes drilled hole checks (hole diameter-to-depth ratio, flat bottoms on holes, perpendicular entry surfaces, holes that intersect internal cavities, partial holes, tolerance checks), milled feature checks (deep pockets and slots, inaccessible features, sharp internal corners, fillets on outside edges) and standard hole size checks (checks hole and available tooling). Therefore, the following DFM rules were verified: Hole Depth/Diameter Ratio, Inaccessible Features, Mill Sharp Internal Corners, Deep Pocket/Slot, Holes with Flat Bottom, Fillets on Outside Edges, Standard Hole Sizes, Partial Hole Rule, Hole Entry/Exit Surface and Hole Intersects Cavity. After running the DFM analysis with the predefined values for the rule parameters, the results can be assessed (Figure 5). It can be observed that 4 rules passed and 6 rules failed. The Partial Hole Rule is respected by the design of the thermoforming mold, which means that the axis of the holes does not intersect any edge of the part or at least 3/4th (75\%) of the holes area is within the material. The fact that the Hole Entry/Exit Surface Rule passed means that the entrance and exit surfaces of all the drilled holes are perpendicular to the holes' axes.
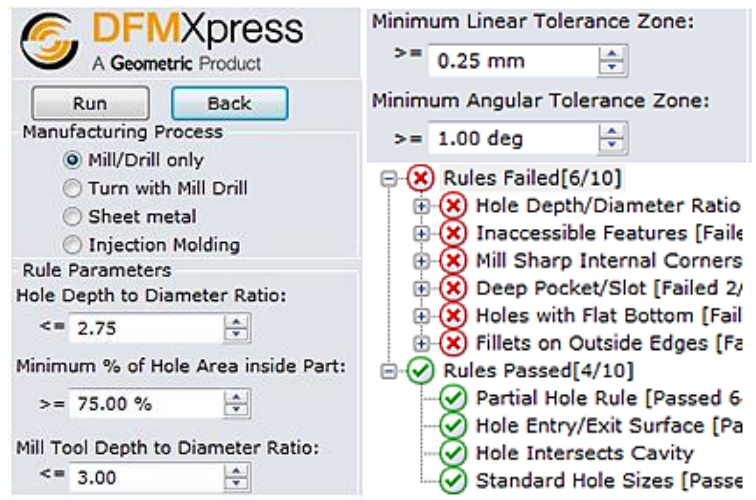

Fig. 5. The obtained DFM results (working with predefined values for Rule Parameters).

It is very important to carefully analyze the failed rules, which represent a suggestion in order to obtain a 3D model which respects the basic DFM axioms. The Hole Depth/Diameter Ratio rule failed due to the fact that the predefined value of 2.75 for this rule parameter was taken into consideration during the DFM analysis. This rule is not respected by the $\phi 1 \mathrm{~mm}$ through holes with the depth of $5 \mathrm{~mm}$ (Figure 6), because the Hole Depth to Diameter Ratio in this case is 5 whereas the maximum recommended ratio is 2.75 . Although deep holes are difficult to machine and the chip removal becomes difficult to be removed while drilling these types of holes. These through holes are essential due to the fact that these holes guarantee the adherence of the plastic foil to the bottom of the thermoforming mold in which the plastic container gets its shape. The only solution could be the increase of the holes diameter, which is impossible due to the fact that a higher diameter of these holes would leave marks on the surface of the obtained plastic container which cannot be accepted from the esthetical point of view. By taking into consideration the fact that an HSS micro drill with the diameter of $\phi 1$ $\mathrm{mm}$ and usable length of $6.8 \mathrm{~mm}$ can be used in order to drill these through holes, this rule can be accepted without any modification regarding to the design of the thermoforming mold. 
Inaccessible Feature rule failed due to the marked R1 radiuses, presented in the Figure 7. The DFMXpress program considers that the marked features are either not easily accessible for machining (the tool holder assembly is not able to approach the feature and a long slender cutter is required which is not desirable) or require special cutter for machining.

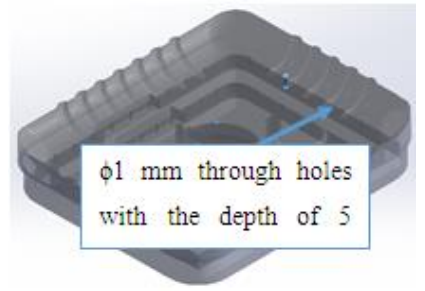

Fig. 6. Failed Hole Depth/Diameter Ratio rule.

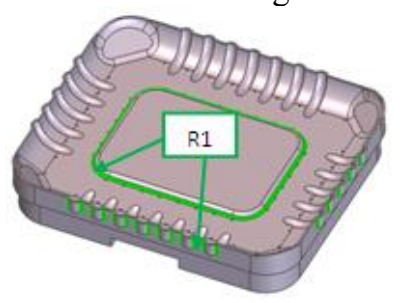

Fig. 7. Failed Inaccessible Feature rule.

\section{Analyzing the effect of the DFM analysis on to the manufacturing time}

Using the DFMXpress program, a redesign of the thermoforming mold was made based on the failed rules and recommendations given by the DFM program. The R1 radiuses, at the outside and at the bottom of the thermoforming mold, were changed, taking into consideration the fact that the Inaccessible Feature rule failed due to these features (Figure 7). The $\mathrm{R} 1$ radius at the bottom of the thermoforming mold was changed into R1.5 radius, therefore the R2 radius of the middle island and the considered R1.5 radius at the part's bottom can be easily machined by using, for both of them, the solid carbide torus cutter with the diameter of $\varnothing 10 \mathrm{~mm}$ and radius of $\mathrm{R} 1.5 \mathrm{~mm}$. This tool will leave a R1.5 radius at the bottom of the thermoforming mold, eliminating therefore the need to use another special tool, the solid carbide torus cutter with the diameter of $\varnothing 4 \mathrm{~mm}$ and radius of R1 $\mathrm{mm}$. Therefore, instead of eliminating the R1 radius from the bottom of the thermoforming mold, it was simpler to modify by increasing it to R1.5 $\mathrm{mm}$, (Figure 8 ).
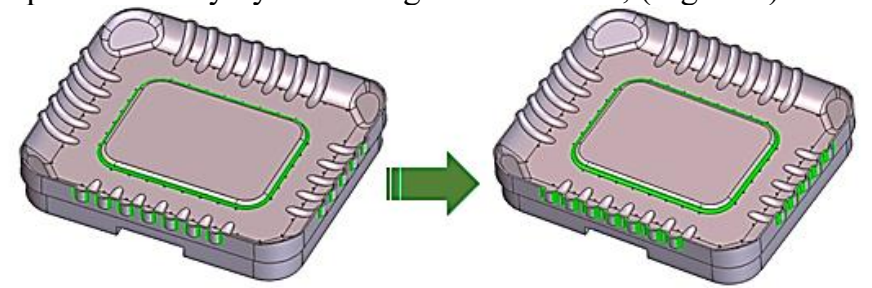

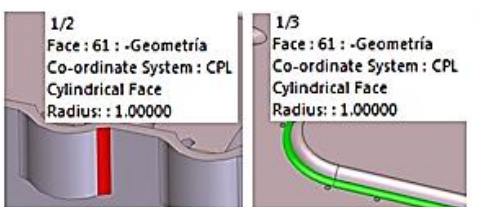

a)

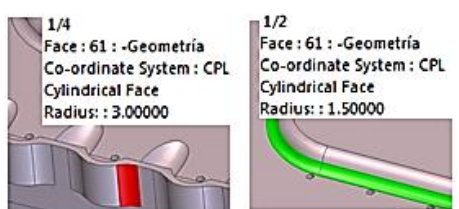

b)

Fig. 8. The redesign of the thermoforming mold based on the recommendations of the DFMXpress program: (a) original design; (b) new design.

Initially, these R1 radiuses were machined by using a solid carbide end-mill with the diameter of $\phi 2 \mathrm{~mm}$, which can be considered an unproductive machining tool due to its small diameter and low feed rate and cut increment. By increasing the size of these exterior $\mathrm{R} 1$ radiuses, it will be easier to be machined with a larger cutter using more productive technological parameters. By taking into consideration the fact that the outside of the 
thermoforming mold was finished with the $\phi 6$ solid carbide end-mill, the increase of the R1 value to R3 would eliminate the necessity to use a rest-profiling operation, eliminating therefore the use of the solid carbide end-mill with the diameter of $\phi 2 \mathrm{~mm}$ at the outside of the thermoforming mold. Due to these modifications, the computer aided manufacturing and the CNC program need to be changed. First of all, the exterior profiling cycle of the R1 radius at the bottom of the thermoforming mold, which initially was realized with the solid carbide torus cutter $\varnothing 4 \mathrm{R} 1$, was eliminated, due to the fact that the R1 radius was modified into R1.5 one. Therefore, the modified radius will be machined during the interior finishing cycle of the thermoforming mold's cavity, realized by the solid carbide torus cutter $\varnothing 10$ R1.5 [5]. This modification has a negligible influence on to the total machining time, as the whole profiling cycle would take only 34 seconds (Figure 9), but still influences the realtime machining, as the CNC operator does not need to prepare, to measure and to set another special tool, the solid carbide torus cutter $ø 4 \mathrm{R} 1$.
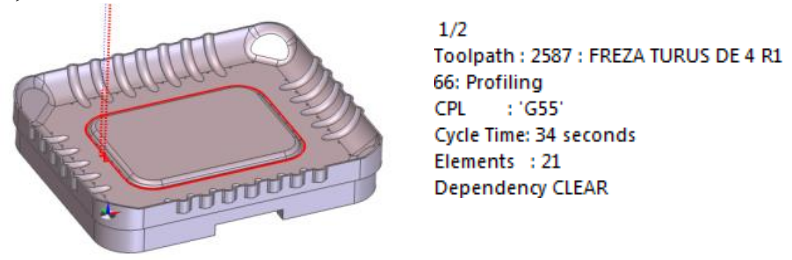

Fig. 9. The solid carbide torus cutter’s $(\varnothing 4 \mathrm{R} 1)$ tool path and the machining time for the profiling operation of the $\mathrm{R} 1$ radius.

Secondly, the exterior rest-profiling cycle of the R1 radiuses at the outside of the thermoforming mold, which were machined with the solid carbide end-mill ø2, was eliminated, due to the fact that the R1 radiuses were modified into R3 ones [5]. Due to this modification, the $\mathrm{R} 3$ radiuses were able to be machined during the exterior profiling cycle, using the solid carbide end-mill with the diameter of $\phi 6 \mathrm{~mm}$ without changing the machining time regarding to this cutting tool. This modification has a considerable influence on to the total machining time, as the whole rest-profiling cycle by using the $ø 2$ solid carbide end-mill would take 32 minutes and 7 seconds (Figure 10). Therefore, by eliminating this rest-profiling cycle, the machining time would be decreased with approximately 32 minutes.

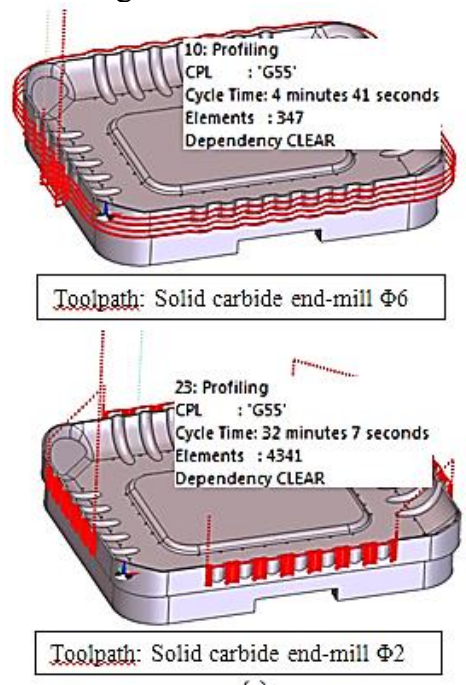

(a)

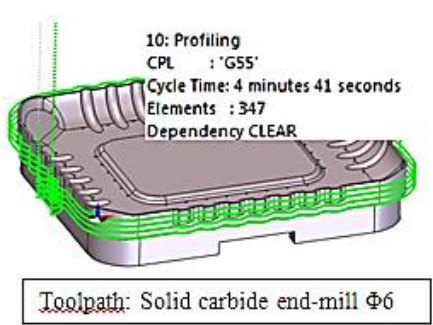

(b)

Fig. 10. Machining time for the: (a) R1 radiuses using a profiling and a rest-profiling cycle (original design); (b) R3 radiuses using only a profiling cyle (new design). 
As it is presented in the Table 1, it was possible to eliminate the critical design issues and therefore to reduce the machining complexity and costs. Therefore, by modifying the $\mathrm{R} 1$ radiuses into $\mathrm{R} 3$ ones and the $\mathrm{R} 1$ radius into $\mathrm{R} 1.5$ one, the manufacturing time was decreased with approximately 33 minutes.

Table 1. The influence of the thermoforming mold's new design (based on DFMXpress recommendations) on to the machining time.

\begin{tabular}{|c|c|c|c|c|c|}
\hline & Used cycle & Profiling Cycle & $\begin{array}{c}\text { Rest - Profiling } \\
\text { Cycle }\end{array}$ & $\begin{array}{l}\text { Profiling } \\
\text { Cycle }\end{array}$ & \multirow{2}{*}{$\begin{array}{l}\text { Total } \\
\text { time }\end{array}$} \\
\hline \multicolumn{2}{|r|}{ Used cutting tool } & $\begin{array}{l}\text { Ф6solid carbide } \\
\text { end-mill }\end{array}$ & $\begin{array}{l}\text { \$2solid carbide } \\
\text { end-mill }\end{array}$ & $\begin{array}{l}\text { } \Phi 4 \text { Rlsolid } \\
\text { carbide torus- } \\
\text { cutter }\end{array}$ & \\
\hline \multirow{2}{*}{$\begin{array}{c}\text { Original } \\
\text { design }\end{array}$} & $\begin{array}{l}\mathrm{Rl}-\text { at the outside of the } \\
\text { thermoforming mold }\end{array}$ & $\begin{array}{c}4 \mathrm{~min} \\
41 \mathrm{~s} \\
\end{array}$ & $\begin{array}{c}32 \min \\
7 \mathrm{~s}\end{array}$ & - & \multirow{2}{*}{$\begin{array}{c}37 \mathrm{~min} \\
22 \mathrm{~s}\end{array}$} \\
\hline & $\begin{array}{l}\mathrm{Rl} \text { - at the bottom of the } \\
\text { thermoforming mold }\end{array}$ & - & - & $34 s$ & \\
\hline \multirow{2}{*}{$\begin{array}{l}\text { New } \\
\text { design }\end{array}$} & $\begin{array}{l}\text { R3 - at the outside of the } \\
\text { thermoforming mold }\end{array}$ & $\begin{array}{c}4 \mathrm{~min} \\
41 \mathrm{~s}\end{array}$ & - & - & \multirow{2}{*}{$4 \min$} \\
\hline & $\begin{array}{l}\text { Rl.5 - at the bottom of the } \\
\text { thermoforming mold }\end{array}$ & - & - & - & \\
\hline
\end{tabular}

\section{Conclusions}

The research presented in this paper was mostly aimed to decrease the manufacturing time of the thermoforming mold by applying optimal tool path strategies and basic DFM principles. A design for manufacturing analysis was realized using DFMXpress in order to identify and eliminate the critical design issues of the thermoforming mold that increase the manufacturing complexity and cost. After running the DFM analysis, the results were assessed, followed by a redesign of the thermoforming mold based on the failed rules and recommendations given by the DFM program. After having a modified design for the thermoforming mold, the benefit effect of the DFM analysis on to the manufacturing time was analyzed. The overall machining time was reduced with approximately 33 minutes for one part, by modifying the R1 radiuses into R3 ones at the outside of the thermoforming mold and the R1 radius into R1.5 one at the bottom of the considered part. Taking into consideration the fact that the required quantity of this thermoforming mold is 25 parts and the manufacturing cost for one hour is equal to 28 euros, it means that the machining time was reduced with 825 minutes (approximately 14 hours) for the whole quantity of parts required to be manufactured. The manufacturing costs were also reduced with 392 euros in total, in this case.

This research was supported by the HORIZON 2020 AMaTUC project (GA 691787) financed from EU.

\section{References}

1. D. M. Anderson, Design for Manufacturability; How to Use Concurrent Engineering to Rapidly Develop Low-Cost, High-Quality Products for Lean Production, CRC Press, New York, (2014)

2. A. Hoque, P. Halder, M. Parvez, T. Szecsi, J. Computers \& Industrial Engineering, 66, 988 (2013)

3. P. Romero, R. Dorado, F. Diaz, E. Rubio, J. Procedia Engineering, 63, 523 (2013)

4. C. Zezhong, F. Qiang, J. Computer Aided Design, 43, 651 (2011)

5. H. Hoffmann Group, Machining/Clamping technology, Main Catalogue (2016/2017) 